\title{
Morphological alterations on human radicular dentin after exposure to different fruit juice drinks
}

\author{
Alterações morfológicas na dentina radicular após exposição a \\ diferentes sucos de fruta
}

\begin{abstract}
Purpose: This in vitro study aimed to evaluate the effect of different fruit juice drinks available in the Brazilian market on smear layer removal and dentinal tubules opening, as well as to verify the effect of toothbrushing subsequently to the juices exposure.

Methods: Dentin specimens were prepared and randomly distributed into the control group (distilled water) and twelve types of fruit juice drinks (cashew, orange, mandarin, apple, passion fruit, guava, strawberry, grape, mango, pear, peach, pineapple). The following treatments were applied: immersion or immersion + brushing. After preparation for SEM, photomicrographs were assessed using an index of smear layer removal.

Results: No significant differences regarding smear layer removal and dentinal tubules exposure could be observed between the groups after both treatments (Kruskal-Wallis, post-hoc paired comparisons, $P>0.05)$. The control solution and the fruit juice drinks were not able to remove smear layer and to open dentinal tubules. Significant difference between the applied treatments was detected only for the mango juice group (Mann-Whitney, $P<0.05$ ).

Conclusion: Under the experimental conditions, the different fruit juice drinks did not promote significant alterations on human radicular dentin morphology regardless of the subsequent application of brushing procedures.
\end{abstract}

Key words: Dentin; dentin sensitivity; acids; diet; smear layer

\section{Resumo}

Objetivo: $O$ objetivo deste estudo in vitro foi avaliar o efeito de diferentes sucos de fruta disponíveis no mercado brasileiro sobre o grau de remoção de smear layer e abertura dos túbulos dentinários, assim como verificar o efeito da escovação realizada imediatamente após a exposição aos sucos.

Metodologia: Amostras de dentina foram preparadas e distribuídas aleatoriamente entre o grupo controle (água destilada) e doze tipos de suco de fruta (caju, laranja, tangerina, maçã, maracujá, goiaba, morango, uva, manga, pêra, pêssego, abacaxi). Os tratamentos aplicados foram: imersão ou imersão + escovação. Após preparo para MEV, fotomicrografias foram avaliadas utilizando-se um índice de remoção de smear layer.

Resultados: Não foram encontradas diferenças significativas entre os grupos em relação à remoção de smear layer e abertura dos túbulos após ambos os tratamentos (Kruskal-Wallis, comparações pareadas, $P>0.05$ ). A solução controle e os sucos de fruta não promoveram remoção de smear layer e abertura dos túbulos dentinários. Apenas no grupo do suco de manga foi verificada uma diferença significativa entre os tratamentos aplicados (Mann-Whitney, $P<0.05)$.

Conclusão: Com base na metodologia utilizada, pode-se concluir que os diferentes sucos de fruta não promoveram alterações significativas na morfologia da dentina radicular apesar da realização subsequente de procedimentos de escovação.

Palavras-chave: Dentina; sensibilidade da dentina; ácidos; dieta; camada de esfregaço

\author{
Daniela Leal Zandim a \\ Cínthia Oliveira Martins a \\ Rodrigo Cavassim a \\ Carlos Rossa Júnior a \\ Ricardo Samih Georges Abi-Rached a \\ José Eduardo Cezar Sampaio a
}

- Araraquara Dental School, São Paulo State University, Araraquara, SP, Brazil

\author{
Correspondence: \\ José Eduardo Cezar Sampaio \\ Departamento de Diagnóstico e Cirurgia, \\ Disciplina de Periodontia \\ Faculdade de Odontologia de Araraquara, UNESP \\ Rua Humaitá, 1680 - Centro - Caixa postal 331 \\ Araraquara, SP - Brasil \\ 14801-903 \\ Email: jsampaio@foar.unesp.br
}

Received: October 6, 2010

Accepted: January 7, 2011

Conflict of Interest Statement: The authors state that there are no financial and personal conflicts of interest that could have inappropriately influenced their work.

Copyright: (C) 2011 Zandim et al.; licensee EDIPUCRS. This is an Open Access article distributed under the terms of the Creative Commons AttributionNoncommercial-No Derivative Works 3.0 Unported License. 


\section{Introduction}

The professional is frequently sought by patients that experience short and sharp pain during the consumption of either cold or sweet food, breathing and even when brushing their teeth. This painful condition arising from exposed dentin in response to stimuli typically thermal, evaporative, tactile, osmotic or chemical and which cannot be ascribed to any other form of dental defect or disease is defined as dentin hypersensitivity (DH) (1). The hydrodynamic theory proposed by Brännström et al. is the most widely accepted mechanism to explain the transmission of pain through dentin. According to this theory, the inward or outward directional movement of the dentinal tubular fluid, is responsible for the stimulation of receptors in the pulp-dentin area, resulting in the generation of pain impulses $(2,3)$.

In normal conditions, dentin is covered by enamel, in the region corresponding to dental crown, and by cementum in the radicular portion of the teeth. Therefore, two conditions are essential for the development of $\mathrm{DH}$ : dentin must become exposed through either loss of dental structure (enamel or cementum) or gingival recession $(2,4)$, and the dentinal tubules must be open to both the oral cavity and the pulp $(1,5,6)$.

Many factors may be associated with dentin exposure and with dentinal tubules opening. Although these factors have been clarified; little emphasis has been dedicated to the knowledge and identification of the etiologic factors of $\mathrm{DH}$, which are essential for prevention and treatment of this painful condition. The patient's diet has been considered one of the most important etiologic factors of DH. The frequent ingestion of acidic food and drinks can cause tooth wear (erosion) (7-10) or rapid loss of smear layer resulting in the wide opening of dentinal tubules $(2,6,11-15)$. Since the frequency ingestion of specific food and acidic drinks was associated with the persistence of DH (12), the nutritional advisement has been considered an important part of DH treatment $(1,5,6,12)$.

Overall, the consumption of soft acidic drinks and healthy diets (often acidic) has increased. Fruit juice drinks (not 100 percent natural juice) have been widely consumed by both children and adults. Thus, the objectives of the present in vitro study were to evaluate the influence of different types of fruit juice drinks available in the Brazilian market upon smear layer removal and dentinal tubules opening, and to evaluate the effect of toothbrushing subsequently to the juice drinks exposure.

\section{Methodology}

\section{Specimens preparation}

Forty-four human teeth recently extracted for periodontal reasons were used. The exclusion criteria for tooth selection were: teeth with crack, caries, or restorations bellow the cementum-enamel junction, and teeth with developmental radicular anomalies. Only single and multi-rooted teeth from non-smoking patients were included in the experiment. The teeth were obtained after informed consent of the patients and under the protocol approved by the Ethics Committee of the Araraquara Dental School/UNESP.

The dentin specimens were prepared as described by Corrêa et al. (13). High-speed diamond-coated burs $\left(n^{\circ}\right.$ 3202, KG Sorensen, Barueri, SP, Brazil) were used to remove the cementum from the cervical region of the roots. Subsequently, the roots were instrumented with forty shaving strokes in each surface using Gracey's curettes 5-6 (Hu-Friedy, Chicago, IL, USA) by the same operator in order to create smear layer. The roots were reduced with a diamond disk (KG Sorensen, Barueri, SP, Brazil) to obtain three dentin specimens from each tooth $\left(3 \times 3 \times 2 \mathrm{~mm}^{3}\right)$. A total of 130 specimens were prepared and stored in a container with phosphate-buffered saline $\mathrm{pH} 7.4$ at $37^{\circ} \mathrm{C}$ for a maximum of 1 week until the treatments were carried out.

\section{Specimens Treatment}

The specimens were randomly allocated into the control group (distilled water) and twelve experimental groups of fruit juice drinks: cashew, orange, mandarin, apple, passion fruit, guava, strawberry, grape, mango, pear, peach, pineapple. The $\mathrm{pH}$ was determined by a single electrode $\mathrm{pH}$ meter ( $\mathrm{pH}$ Meter, UB-10, Denver Instrument, Arvada, Colorado, USA) immediately after the juice drink opening. The electrode was calibrated using standard buffers of 4.0 and 7.0. Each group was subdivided into two subgroups according to the applied treatment (13-15):

- Immersion: immersion in distilled water or fruit juice drink $(25 \mathrm{~mL})$ for 5 minutes and rinsing with $15 \mathrm{~mL}$ of distilled water;

- Immersion + Brushing: immersion in distilled water or fruit juice drink $(25 \mathrm{~mL})$ followed by manual brushing of the specimens with a soft toothbrush (Colgate, São Bernado do Campo, SP, Brazil) by the same operator for 30 seconds, and rinsing with $15 \mathrm{~mL}$ of distilled water.

For SEM analysis (Jeol T330 A, Jeol Ltd., Peabody, MA, USA), the specimens were dehydrated in ethanol solutions (Merck, Darmstadt, Germany) of increasing concentration (30, 50, 70, 80, 95 and 100\%), dried overnight in a dehydration jar (Corning, São Paulo, Brazil), mounted on metallic stubs (Senai, São Paulo, Brazil) and sputter-coated with gold. Two photomicrographs were obtained from the center of each specimen with magnifications of 750 and 1500x. The photomicrographs were assessed by an examiner previously calibrated and blinded to the experimental groups using an index of smear layer removal (13-15):

- Score 1 - Complete removal of smear layer, dentinal tubules open;

- Score 2 - Partial removal of smear layer, dentinal tubules partially open;

- Score 3 - Smear layer present on the dentin surface, indication of dentinal tubules open;

- Score 4-Smear layer present on the dentin surface, total obliteration of dentinal tubules; 
The examiner accomplished three consecutive readings, with intervals of one week, for each photomicrograph. The predominant score of the three readings was considered representative of the respective specimen. The Kappa test was applied twice after scoring subsets of specimens to check the calibration of the examiner and the reproducibility of the readings, in order to assure the consistency of the evaluation.

\section{Statistical Analysis}

The data were obtained using an index representing a scoring system, thus non-parametric analyses were applied. The evaluation of the treatment factor influence on the scores attributed to the specimens was performed by a non-parametric analysis of variance (Kruskal-Wallis), followed by a test of multiple comparisons (Dunn's test). In addition, the MannWhitney test was applied to compare the results of the applied treatments for each group. A 5\% confidence level was used.

\section{Results}

The $\mathrm{pH}$ values of the control solution and the different fruit juice drinks are depicted in Table 1. The frequency distribution of scores within each group treated by immersion is illustrated in Figure 1. No significant differences regarding smear layer removal and dentinal tubules exposure could be observed between the control group and the fruit juice drinks (Kruskal-Wallis, post-hoc paired comparisons, $P>0.05)$. After exposure to the fruit juice drinks, the dentinal tubules were completely obliterated (Score 4) (Fig. 2), with exception of the guava and mango groups that demonstrated predominance of the specimens with indication of dentinal tubules opening (Score 3) (Fig. 3). The results obtained after immersion + brushing were similar to those obtained after immersion only (Fig. 4). No statistically significant differences could be verified between the groups (KruskalWallis, post-hoc paired comparisons, $P>0.05$ ). The prevalent scores after immersion + brushing were 3 and 4 (Fig. 5 and 6).

The comparison between the applied treatments using the Mann-Whitney test showed significant difference for the mango group only $(P=0.006)$. In this group, indication of dentinal tubules opening could be observed after immersion (Score 3) (Fig. 3), while the dentinal tubules were completely obliterated (Score 4) after immersion + brushing (Fig. 5).

Table 1. $\mathrm{pH}$ value of the control solution and the fruit juice drinks.

\begin{tabular}{lc}
\hline \multicolumn{1}{c}{ Main substance in the drinks } & $\mathrm{pH}$ \\
\hline Cashew* $^{*}$ & 3.66 \\
Orange $^{\#}$ & 3.90 \\
Mandarin $^{*}$ & 4.00 \\
Apple* $^{*}$ & 3.62 \\
Passion fruit* & 2.99 \\
Guava* $^{*}$ & 3.63 \\
Strawberry§ & 4.32 \\
Grape* $^{*}$ & 2.96 \\
Mango* $^{*}$ & 3.54 \\
Pear & 3.99 \\
Peach* & 3.77 \\
Pineapple & \\
Control (distilled water) & 4.09 \\
\hline
\end{tabular}

${ }^{*}$ Suco Mais ${ }^{\circledR}$.

\# Suco Ades ${ }^{\circledR}$

$\S$ Suco Tonyu Yakult ${ }^{\circledR}$.

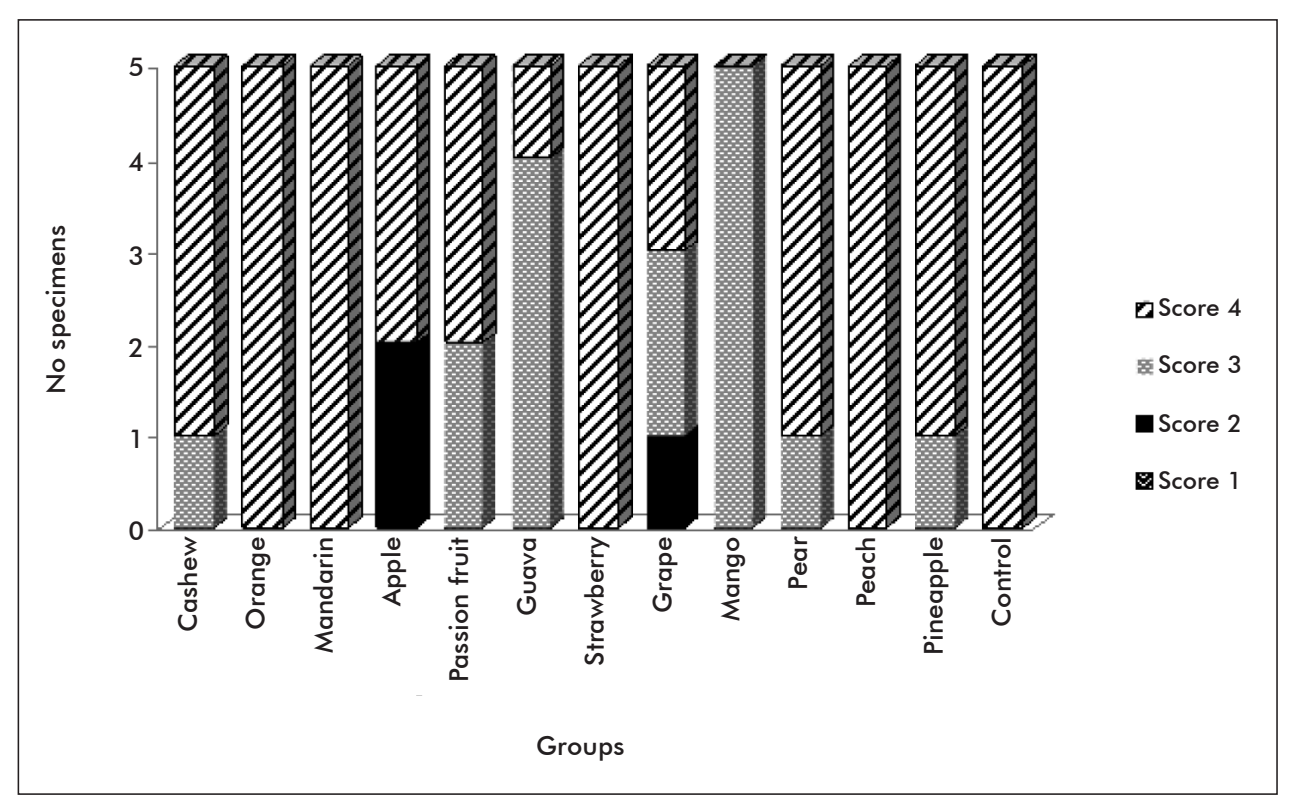

Fig. 1. Frequency distribution of scores for specimens treated by immersion according to the group. 


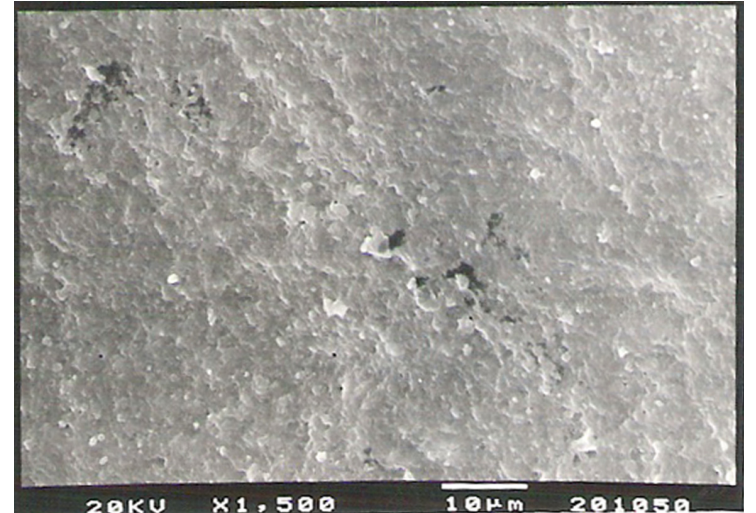

Fig. 2. Dentin surface covered by smear layer with dentinal tubules completely obliterated after treatment by immersion. Representative photomicrograph of control group (distilled water) and cashew, orange, mandarin, apple, passion fruit, strawberry, pear, peach, pineapple groups (Score 4).

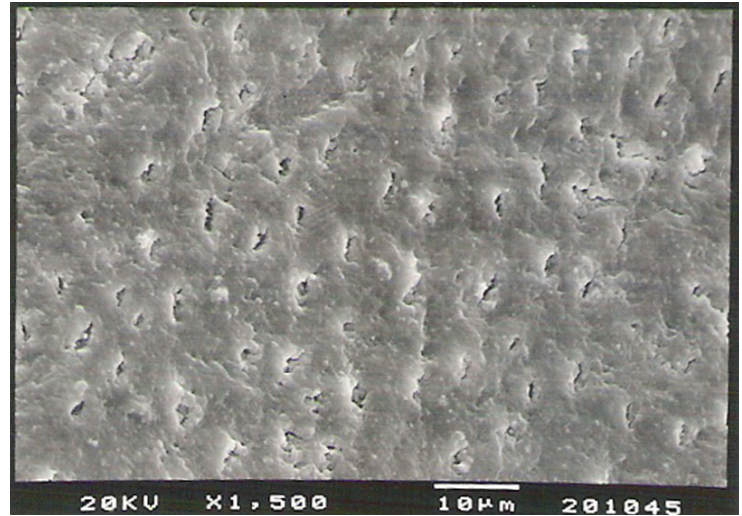

Fig. 3. Dentin surface covered by smear layer with indications of dentinal tubules opening after treatment by immersion. Representative photomicrograph of mango and guava groups (Score 3).

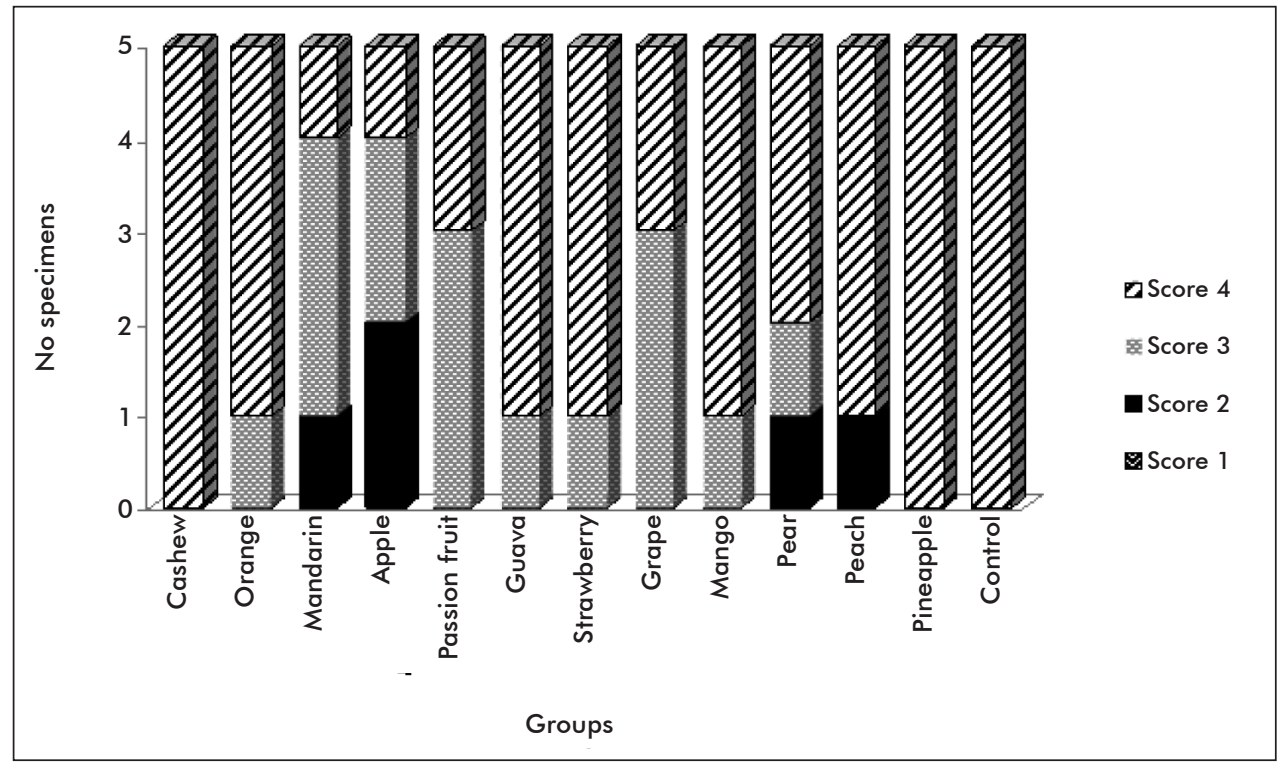

Fig. 4. Frequency distribution of scores for specimens treated by immersion + brushing according to the group.

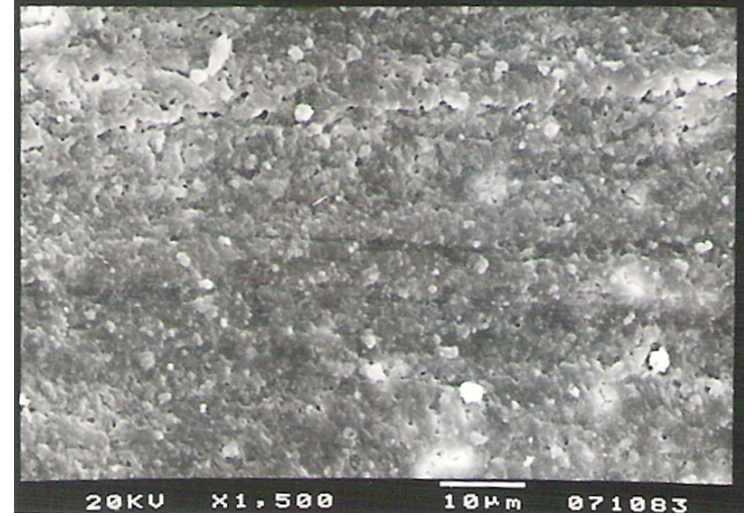

Fig. 5. Dentin surface covered by smear layer with dentinal tubules completely obliterated after treatment by immersion + brushing. Representative photomicrograph of control group (distilled water) and cashew, orange, guava, strawberry, mango, pear, peach, pineapple groups (Score 4).

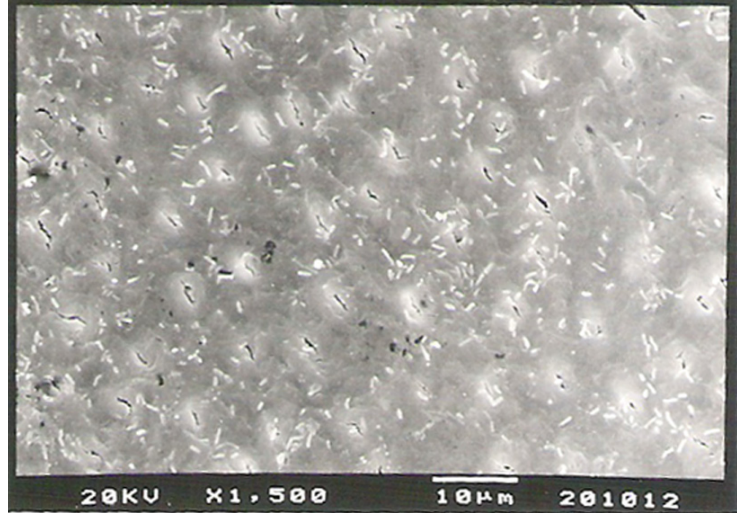

Fig. 6. Dentin surface covered by smear layer with indications of dentinal tubules opening after treatment by immersion + brushing. Representative photomicrograph of mandarin, passion fruit and grape groups (Score 3). 


\section{Discussion}

The hydrodynamic mechanism requires that dentinal tubules are open at the dentin surface and patent to the pulp to ocurr $\mathrm{DH}(2,3)$. This fact explains why many people have exposed dentin, but they do not suffer from DH. Previous studies showed the characteristics of sensitive and nonsensitive areas of exposed dentin. In sensitive dentin, the tubules are completely open, and the number ( 8 times) as well as the diameter (2 times) of tubules are greater than the tubules of non-sensitive dentin. On the other hand, few tubules, smaller in diameter and usually blocked, are observed in the non-sensitive teeth $(6,16-18)$. Therefore, the identification of factors that render dentin exposed and tubules open is important both to the prevention and the management of DH.

In the present in vitro study, our intention was to verify whether different fruit juice drinks available in the Brazilian market could remove smear layer and open dentinal tubules. In principle, any physical or chemical force that promotes the loss of smear layer and the opening of dentinal tubules can initiate a hypersensitive lesion. The smear layer was created in this experiment by manual scaling of root surfaces with curettes, and two treatments were applied (13-15). The treatment by immersion was used to simulate the contact of exposed dentin (covered by smear layer) with acidic drinks, while treatment by immersion + brushing was used to evaluate the effects of toothbrushing subsenquently to the fruit juice drink exposure. No significant differences could be observed between the control group and the fruit juice drinks regarding smear layer removal and dentinal tubules opening after both treatments. Our SEM observations demonstrated that the dentinal tubules were completely obliterated (Score 4) after exposure to almost fruit juice drinks. In few groups, indications of dentinal tubules opening (Score 3) could be observed (Fig. 1 and 4).

The methodology of the present study was previously used to evaluate the effect of 100 percent natural fruit juices on smear layer removal (13). It was verified that lemon ( $\mathrm{pH} 2.2)$, kiwi ( $\mathrm{pH} 3.2)$, acerola $(\mathrm{pH} 2.8)$, orange $(\mathrm{pH} 3.8)$ and green apple $(\mathrm{pH} 3.6)$ natural juices induced significantly higher smear layer removal than the control group ( $\mathrm{pH}$ 5.9). On the other hand, Gala apple ( $\mathrm{pH} 4.2$ ) and Italian grape natural juices $(\mathrm{pH} 3.7)$ were not different from control and predominantly resulted in Scores 3 and 4. Absi et al. (11) have also observed that lemon, apple, and orange juices promote the opening of many dentinal tubules. Prati et al. (19) verified that the single exposure of dentin to acidic drinks (cola drink, orange fruit juice, white wine, vinegar and mucolytic syrup) for a relative short time (5 min) was sufficient to remove the smear layer and to induce several alterations to the dentin surface, such as dentinal tubules opening, removal of dentin plugs, increase of tubule diameter, removal of organic intertubular dentin, and collagen exposure.

Despite the low $\mathrm{pH}$ values (Table 1), the fruit juice drinks did not cause smear layer removal and dentinal tubules opening. The effect of acids upon dentinal surface is not only exclusively dependent on the $\mathrm{pH}$ value, but also strongly influenced by other factors such as the acid type and its concentration, titratable acidity, temperature, calciumchelating properties, the presence of different types of $\operatorname{sugar}(7,9,10,20)$. According to the manufacturers, the main ingredients of the fruit juice drinks were water, concentrated natural juice, sugar, acidulating substances (citric acid) and natural aroma. The dilution with water of drinks containing organic acids with high buffering capacity had very little effect on the measured $\mathrm{pH}$ values, but considerably reduced the titratable acidity (21). This fact could explain the results obtained in the present study. The presence of certain inorganic ions can have a protective role by maintaining a high level of saturation with respect to tooth mineral (4). Some studies showed that the erosive potential of drinks is associated with their calcium and phosphate concentrations $(7,9,21)$. However, the tested fruit juice drinks did not contain calcium and phosphate (according to the manufacturer's description).

Other evaluated aspect of this study was the effect of toothbrushing (without dentifrice) immediately after the exposure of dentin to the fruit juice drinks. In the presence of acids, toothbrushing can accelerate both the process of erosion and the tubule opening. The surface that becomes demineralized by the action of the acid is more vulnerable to the action of abrasive substances $(11,22,23)$. For this reason, toothbrushing should not be performed after the consumption of acidic foodstuffs or beverages $(11,23)$. The Canadian Advisory Board on Dentin Hypersensitivity recommends brushing procedures before meals (1). No significant difference could be detected between the applied treatments, except for the mango group. In this group, the difference occurred because all specimens showed Score 3 after immersion and Score 4 after immersion + brushing (Fig. 1 and 4). However, in fact, the tested fruit juice drinks did not remove the smear layer present on dentin surface after an exposure period of 5 minutes and the brushing procedures did not promote tubules exposure.

Generally, the professional does not consider the identification of etiological or possible predisposing factors on DH treatment. If the predisposing factors were not removed or modified, the treatment could provide only short-term success. It is well established that patient's diet is an important aetiological factor of dentin hypersensitivity. The frequent and excessive consumption of acids should be avoided by patients with exposed dentin. Since the application of the different fruit juices drinks did not remove smear layer and open dentinal tubules, these drinks may not induce significant alterations in exposed dentin in vivo.

\section{Conclusions}

Within the limits of the present study, it can be concluded that the different fruit juice drinks did not cause significant morphological alterations on human radicular dentin surface. 
After exposure to the fruit juice drinks, the dentin surfaces were characterized by complete obliteration of dentinal tubules or by indications of dentinal tubules opening, regardless the brushing procedure.

\section{References}

1. Canadian Advisory Board on Dentin Hypersensitivity. Consensus-based recommendations for the diagnosis and management of dentin hypersensitivity. J Can Dent Assoc 2003;69:221-6.

2. Brannstrom M. The hydrodynamic theory of dentinal pain: sensation in preparations, caries, and the dentinal crack syndrome. J Endod 1986;12:453-7.

3. Brännström M, Aström A. The hydrodynamics of the dentine, its possible relationship to dentinal pain. Int Dent J 1972;22:219-27.

4. Grenby TH. Lessening dental erosive potential by product modification. Eur J Oral Sci 1996;104:221-8.

5. Addy M, Urquhart E. Dentine Hypersensitivity: its prevalence, aetiology and clinical management. Dent Uptade 1992;19:407-12.

6. Rimondini L, Baroni C, Carrassi A. Ultrastructure of hypersensitive and non-sensitive dentine. A study on replica models. J Clin Periodontol 1995;22: 899-902.

7. Larsen MJ, Nyvad B. Enamel erosion by some soft drinks and orange juices relative to their $\mathrm{pH}$, buffering effect and contents of calcium phosphate. Caries Res 1999;33:81-7.

8. Lussi A, Jaeggi T. Erosion-diagnosis and risk factors. Clin Oral Investig 2008;12 (Suppl 1): S5-13.

9. Lussi A, Jaeggi T, Jaeggi-Schärer S. Prediction of the erosive potential of some beverages. Caries Res 1995;29:349-54.

10. Lussi A, Kohler N, Zero D, Schaffner M, Megert B. A comparison of the erosive potential of different beverages in primary and permanent teeth using an in vitro model. Eur J Oral Sci 2000;108:110-4.

11. Absi EG, Addy M, Adams D. Dentine hypersensitivity - the effect of toothbrushing and dietary compounds on dentine in vitro: an SEM study. J Oral Rehabil 1992;19:101-10.

12. Clark DC, Woo G, Silver JG, Sweet D, Grisdale JC. The influence of frequent ingestion of acids in the diet on treatment for dentin sensitivity. J Can Dent Assoc 1990;56:1 101-3.

13. Corrêa FO, Sampaio JE, Rossa Júnior C, Orrico SR. Influence of natural fruit juices in removing the smear layer from root surfaces - an in vitro study. J Can Dent Assoc 2004; 70:697-702.

14. Zandim DL, Corrêa FO, Sampaio JE, Rossa Júnior C. The influence of vinegars on exposure of dentinal tubules: a SEM evaluation. Braz Oral Res 2004; 18:63-8.

15. Zandim DL, Corrêa FO, Rossa Júnior C, Sampaio JE. In vitro evaluation of the effect of natural orange juices on dentin morphology. Braz Oral Res 2008;22:176-83.

16. Absi EG, Addy M, Adams D. Dentine hypersensitivity. A study of the patency of dentinal tubules in sensitive and non-sensitive cervical dentine. J Clin Periodontol 1987;14:280-4.

17. Absi EG, Addy M, Adams D. Dentine hypersensitivity. The development and evaluation of a replica technique to study sensitive and non-sensitive cervical dentine. J Clin Periodontol 1989;16:190-5.

18. Yoshiyama M, Masada J, Uchida A, Ishida H. Scanning electron microscopic characterization of sensitive vs. insensitive human radicular dentin. J Dent Res 1989;68:1498-502.

19. Prati C, Montebugnoli L, Suppa P, Valdrè G, Mongiorgi R. Permeability and morphology of dentin after erosion induced by acidic drinks. J Periodontol 2003;74:428-36.

20. West NX, Hughes JA, Addy M. Erosion of dentine and enamel in vitro by dietary acids: the effect of temperature, acid character, concentration and exposure time. J Oral Rehabil $2000 ; 27: 875-80$.

21. Cairns AM, Watson M, Creanor SL, Foye RH. The $\mathrm{pH}$ and titratable acidity of a range of diluting drinks and their potential effect on dental erosion. J Dent 2002;30:313-7.

22. Hughes JA, West NX, Parker DM, Newcombe RG, Addy M. Development and evaluation of a low erosive blackcurrant juice drink. 3. Final drink and concentrate, formulae comparisons in situ and overview of the concept. J Dent 1999;27:345-50.

23. Davis WB, Winter PJ. The effect of abrasion on enamel and dentine after exposure to dietary acid. Br Dent J 1980; 148: 253-6.

24. McAndrew R, Kourkouta S. Effects of toothbrushing prior and/or subsequent to dietary acid application on smear layer formation and the patency of dentinal tubules: an SEM study. J Periodontol 1995;66:443-8. 